\title{
Sponge Carrying by Dolphins (Delphinidae, Tursiops sp.): A Foraging Specialization Involving Tool Use?
}

\author{
RACHEI. SMOLKER, ANDREW RICHARDS, RichaRd CONNOR, JANET MANN \& \\ PER BERGGREN
}

SMOliker, R., Richards, A., CONNOR, R., MANN, J. \& Berggren, P. 1997: Sponge catrying by dolphins (Delphinidae, Tursiops sp.): a foraging specialization involving tool use? Ethology 103, 454-465.

\begin{abstract}
During long-term research on bottlenose dolphins (Tursiops sp.) in Shark Bay, Western Australia, sevcral individuals were observed carrying sponges, Echinodictym mesenterinum, on their rostra. Over multiple years, five regularly sighted individuals were usually carrying sponges when encountered $(67-100 \%$ of encounters). Four additional regularly sighted individuals were observed with sponges just one time each. $A$ il five individuais that routinely carried sponges were female. Two of the anomalous, one-time carriers were fematc, one was likely female, and one was male. Most observations of sponge carrying occurred within a restricted area, a relatively deep water channel ( $8-10 \mathrm{~m}$ deep). Surface observations of sponge carrying, including focal animal observations, revealed a stereotyped surfacing and diving pattern, and occasional indications of prey consumption. Threc hypotheses are considered retgarding the function of sponge carrying: 1. dolphins werc playing with the sponges; 2. the sponges contain some compound of use to the dolphins (e.g. for medicinal purposes); and 3. the sponges were used as a tool to aid in foraging. The foraging tool hypothesis is best supported, but the exact manner in which sponges are used remains to be discovered. Sponge carrying is a behavioural specialization, probably involving foraging, and regularly engaged in by only a small proportion of female dolphins in Shark Bay.
\end{abstract}

Corresponding author: Rachel SMOLKFr, Biology Dept., Marsh Life Sciences Bldg., University of Vermont, Burlington, Vermont 05405-0086, USA. E-mail: rsmolker@zoo.uvm.edu

\section{Introduction}

Since 1984, we have repeatedly observed some members of a population of bottlenose dolphins in Shark Bay, Western Australia, cartying sponges on their rostra. In this paper, we provide a description of the behaviour and determine the distribution of sponge carrying across individuals and locations within our study site.

Because sponges carried by the dolphins are often quite large, covering a large portion of the dolphins' face, they must interfere with normal use of the mouth, contribute to hydrodynamic drag, and might interfere with production and reception of sounds used for echolocation. We therefore assume that it is a costly behaviour and must be counterbalanced by some functional advantage, i.e. the dolphins must 'use' the sponges somehow. Although 
we have not yet been able to determine how, we discuss what we believe to be the most plausible scenarios in light of our observations.

\section{Methods}

Our study site is an area of approximately $150 \mathrm{~km}^{2}$ offshore of the Monkey Mia camp on the cast cost of the Peron Peninsula that bisects Shark Bay in Western Australia (27 $47^{\prime} \mathrm{S}, 113^{\circ} 43^{\prime} \mathrm{E}$ ). Several dolphins (ranging in number from four to eight) regularly enter shallow water at the Monkey Mia beach where they accept fish fed by hand (CONNOR \& SMOI.KJ:R 1985; SMOI.KER ct al. 1992). Over 400 additional dolphins in the area do not come into Monkey Mia. Photographic records of nicks and scars as well as distinctive shapes of dorsal fins permit us to recognize individuals. Some individuals ate seen almost every day, and others are seen rarely. Many of the most commoniy sighted dolphins have been subjects of long-term focal data collection (Ai.TMANN 1974). Sexes have been determined either by direct observation of external genital morphology (dolphins swim upside down at the bow of our boat, making their genital areas visible), by observation of an erect penis, or by consistent association of an adult with a calf (SMOLKFR et al. 1992; MANN 1995; RICHARDS 1996).

We observed sponge carrying from small $(4 \mathrm{~m})$ boats during both surveys and focal observations. Surveys entailed travelling around the study area in search of dolphins. Because group composition changes often in the course of a day, we refer to these temporary groups as 'parties' (SMOLKER et al. 1992). We considered dolphins to be members of a party if they were within $10 \mathrm{~m}$ of each other at some point during (generally throughout) the first $5 \mathrm{~min}$ of an encounter. When we encountered parties, we noted membership, activity, focation, and recorded ad lib. observations of behaviour prior to continuing on in search of other parties or beginning focal observations on a party member.

Focal observations entailed watching a single individual for as long as possible during the course of a day (ranging from 1 to $10 \mathrm{~h}$ ), recording data on group composition, activity, location, details of surfacing and diving patterns, and social interactions. We occasionally recorded underwater sounds from sponge-carrying dolphins using a system with flat response to about $15 \mathrm{kHz}, \pm 3 \mathrm{~dB}$.

Unless otherwise indicated, the following report is based on observations during $6 \mathrm{jr}$, from 1984 through 1989, the time period during which the behaviout was first discovered and was the subject of systematic study. We observed sponge carrying primarily by means of surveys from 1984 to 1986, and by both surveys and focal observations of sponge carriers thereafter.

\section{Results}

Table 1 summarizes observations of sponge carrying. Over 6 y we observed sponge carrying 75 times (if an animal was observed more than once during a day, only the first sighting was counted). Of these, 27 marked the beginning of focal observation on the sponge carrier $(73 \mathrm{~h}$ of focal data were collected) and the rest were survey sightings.

Five individuals (top of Table 1) were observed carrying sponges repeatedly across multiple years and are hereafter referred to as 'regular sponge carriers'. Table 1 shows the proportion of the total number of observations for each of these dolphins when it carried a sponge. These five regular sponge carriers were rarely seen without sponges during the entire 6 yr period. During the same period, we conducted $1292 \mathrm{~h}$ of focal observation on 60 dolphins and 1095 survey sightings. Sponge carrying by individuals other than the five regular sponge-carriers was observed on only four occasions, involving four different individuals (bottom of Table 1, and described below). Sponge carrying, therefore, is a behavioural specialization engaged in consistently by only a very small proportion of the population.

Sponge carrying was engaged in almost exclusively by females. All five of the regular sponge carriers were female and they accounted for $95 \%$ of observations of sponge carrying. Of the remaining four seen with sponge one time only, two were known to be 
Table 1: Surnmary of observations of sponge carrying dolphins from 1984 to 1989. Regular sponge carriers were repeatedly observed with sponges over multiple years. Anomalous sponge carriers were observed carrying sponge only once each

\begin{tabular}{|c|c|c|c|c|c|c|c|}
\hline Dolphin ID & Sex & $\begin{array}{l}\text { Total d } \\
\text { sighted }\end{array}$ & $\begin{array}{l}\text { No. of } \\
\text { sightings } \\
\text { carrying } \\
\text { sponge }\end{array}$ & $\begin{array}{c}\% \text { sightings } \\
\text { carrying } \\
\text { sponge }^{1}\end{array}$ & $\begin{array}{c}\text { Focal } \\
\text { d }\end{array}$ & $\begin{array}{l}\text { ervation } \\
\mathrm{h}\end{array}$ & Ycars observed \\
\hline \multicolumn{8}{|c|}{$\begin{array}{l}\text { Regular } \\
\text { sponge carriers }\end{array}$} \\
\hline HAL & $\mathrm{F}$ & 30 & 26 & 96 & 9 & 25.4 & $1984-1985,1987-1989$ \\
\hline BYT & $\mathrm{F}$ & 25 & 19 & 86 & 9 & 20.2 & 1985-1989 \\
\hline SPO & $\mathrm{F}$ & 13 & 11 & 100 & 2 & 7.2 & $1984-1989$ \\
\hline GUM & $\mathrm{F}$ & 12 & 8 & 67 & 5 & 16.7 & $1985,1987-1989$ \\
\hline $\mathrm{MOO}$ & $\mathrm{F}$ & 8 & 7 & 88 & 2 & 3.6 & $1984-1985,1988$ \\
\hline Total & & & 71 & & 27 & 73.1 & \\
\hline \multicolumn{8}{|c|}{$\begin{array}{l}\text { Anomalous } \\
\text { sponge carriets }\end{array}$} \\
\hline PUC & $\mathrm{F}$ & 288 & 1 & 0.3 & 2 & 8.0 & $1984-1989$ \\
\hline PDX & $\mathrm{F}$ & 71 & 1 & 1.4 & 3 & 16.0 & $1984-1989$ \\
\hline $\mathrm{DBH}$ & F? & 50 & 1 & 2.0 & 0 & 0 & $1984-1986$ \\
\hline SPU & M & 22 & 1 & 4.6 & 0 & 0 & $1987-1989$ \\
\hline Total & & & 4 & & 5 & 24.0 & \\
\hline
\end{tabular}

'Proportion of time carrying sponges for regular sponge carricrs calculated as the proportion of sightings during which the dolphin carried a sponge out of the total number of times she was seen. A small number of very brief sightings for some females ( 3 for HAL, 3 for BYT, 2 for SPO) were excluded because it was not determined whether she had a spongc or not. Proportion of time carrying sponges for anomalous sponge carriers calculated as the reciprocal of the number of days sighted. Sightings were only counted if they were the first of the day for that individual, and in the case of anomalous sponge carriers, they did not occur during focal observation of another individual (slightly elevating the proportion of time carrying sponge by anomalous carriers relative to regulars).

female, one (DBH) was probably female, based on her behaviour (SMOLKFR et al. 1992), and the remaining individual (SPU) was known to be male (a very brief and anomalous sighting, described below).

The habitat ranges from shallow sand and seagrass flats ( $0-4 \mathrm{~m}$ deep. depending on tide) to deeper basins and channels (up to $12 \mathrm{~m}$ deep). Sand and seagrass flats up to $1 \mathrm{~km}$ wide extend from shote, and offshore flats are surrounded by deeper water. Basins and channels are generally bottomed with silt, sand, or shell and rock rubble. Of 69 sponge carrying observations for which location data were available, 67 occurred in a channel (8$10 \mathrm{~m}$ deep) adjacent to a seagrass bank northeast of Monkey Mia. Two observations of one regular sponge carrier occurred in a moderately deep $(4-5 \mathrm{~m})$ portion of a basin, NW of Monkey Mia.

Sponge carrying occurs in other areas outside our usual range. As we have expanded our study area (since 1989), we have encountered sponge carriers in various other locations 
within Shark Bay. In 1991, two previously unfamiliar females with sponges (both accompanied by calves) were observed on the far side of a shallow bank that forms the northern edge of the channel where most sponge carrying observations were made. One of these females was seen again the following year with sponge. In 1991, a female (accompanied by a calf) was observed carrying a sponge $2 \mathrm{~km}$ west of Faure Island, approximately $10 \mathrm{~km}$ from our usual study area. On two occasions, once in 1991 and once in 1992, unidentified, lone dolphins were observed carrying sponges offshore of the tip of Peron Point, approximately $30 \mathrm{~km}$ from our usual study area. Finally, Dr J. HOOPER of Queensland Museum (pers. comm.) reported a second-hand observation of “... what is probably an Indian Ocean bottlenose dolphin carrying large, globular, red sponges on top of their beaks" near Darwin, Northern Territory, Australia.

Sponges carried by dolphins appeared to be of a single variety. It was frequently possible to get close-up views and photographs (Fig. 1) of the sponges carried by dolphins when they surfaced near by with a sponge. Although size, shape and, to some extent, colour of the sponges vary somewhat, they all appeared basically similar. In 1985 and 1988 sponges that looked like the same type were collected from the bottom of the channel. Several other sponges, soft corals, and algae collected from the same location were not familiar to us, suggesting that the fauna and flora within the channel differs considerably from that of adjacent shallower areas, where we were unable to find specimens. Specimens of the sponge (Northern Territory Museum, Darwin specimen number Z3618-20 and Queensland Museum, Brisbane specimen number G304585), including one that was carried by a dolphin, were identified by $\mathrm{Dr} \mathrm{J}$. HOOPER as Echinodictyum mesenterinum (order Poecilosclerida, family Raspailiidae), a species widespread around Australia and throughout the Indo-West Pacific (HoOper 1991).

The sponges used by dolphins are roughly cone-shaped and are carried with the rostrum tip inserted into the apex of the cone, often with the holdfast visible in front.

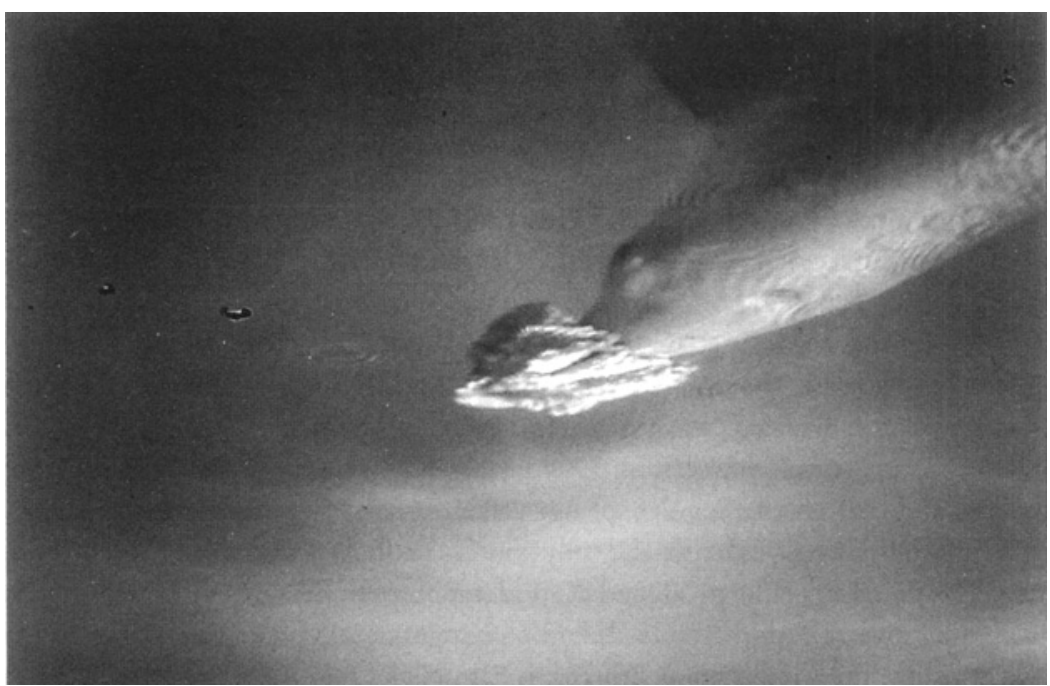

Fig. 1: Dolphin carrying sponge 
Some smaller sponges cover only the tip of the rostrum, while others cover the rostrum and part of the front of the dolphin's head. The sponges are generally a mustard-brown colour and roughly textured with walls approximately $1 \mathrm{~cm}$ thick and very tough. The sponge is not grasped within the jaw, but rather seems to be held in place by virtue of its shape (fitting over the rostrum) and by water pressure as the dolphin moves forward. On four occasions a sponge fell off a dolphin's rostrum as it surfaced to breathe, but was quickly retrieved. During follows, dolphins typically carried the same sponge for multiple surfacings, but occasionally changed sponges. We could not always determine when this happened, but it was clearly observed on at least 20 occasions.

Surface and diving behaviour of regular sponge carriers was stereotyped. To describe this behaviour we generated summary statistics using focal data collected from three regular sponge carriers on $2 \mathrm{~d}$ each ( $6 \mathrm{~d}$ total) during a total of $13 \mathrm{~h} 23 \mathrm{~min}$ (about $4 \mathrm{~h}$ on each animal). Regular sponge-carrying dolphins typically appeared at the surface with a sponge on the rostrum $(68 \%$ of surfacings), took several breaths (range $=1-13$, mean $=4.8$, $\mathrm{SD}=2.3$ ), remaining at or just below the surface while slowly travelling (range of surfacing bout durations $=3-106 \mathrm{~s}$, mean $=29 \mathrm{~s}, \mathrm{SD}=18 \mathrm{~s}$ ), and then dove. They usually brought the flukes out of the water ( $93 \%$ of dives were 'tail-out dives') heading down towards the bottom at a steep angle, and then remained below the surface for $1-2 \mathrm{~min}$ (range $=10 \mathrm{~s}-$ $3 \min 51 \mathrm{~s}$, mean $=1 \min 39 \mathrm{~s}, \mathrm{SD}=43 \mathrm{~s}$ ). This behaviour pattern was repeated for hours at a time.

For comparison, we generated the same summary statistics from $11 \mathrm{~h} 4 \mathrm{~min}$ of focal observations on two individuals that did not carry sponges. One is known female and one is of unknown sex, and both frequented the same area, foraging in a manner that appeared similar to the behaviour of sponge carriers. The surface behaviour of these dolphins differed only in having a lower proportion of tail-out dives (37\%, as compared with $93 \%$ for sponge carriers).

During focal observations, regular sponge carriers sometimes surfaced without a sponge ( $32 \%$ of surfacings). Surfacing bouts without a sponge were often accompanied by slower and less directional travel than surfacing bouts with the sponge. For example, they sometimes performed ' $U$ turns' at the surface, which appeared to be attempts to remain in position over something below (perhaps the sponge). Other, less common surfacings included low leaps, shallow (no tail-out) dives, and fast, single-breath surfacings, usually without a sponge (although this was often difficult to determine given the short time spent at the surface). They were occasionally observed without sponge eating prey at the surface, usually following one of these less common surfacing types.

Monitoring and recording of the underwater vocalizations of dolphins can provide information regarding their activity when the dolphins are out of sight. For example, high rates of echolocation typically accompany foraging, and high rates of 'burst pulse' sounds typically accompany social interactions (OVFRSTROM 1983; SMOLKER 1993). We recorded $123 \mathrm{~min}$ of sounds from three regular sponge carriers on seven different days. Echolocation click trains and a few 'squeals' were the only sounds produced during sponge carrying. The click trains consisted of clicks produced at moderate repetition rates (individual clicks were distinguishable, and repetition rates did not change rapidly). Squeals consisted of very rapidly increasing, then decreasing repetition rate clicks (as the repetition rate increases, individual clicks are no longer distinguishable). Although we could not observe behaviour 
associated with the squeals produced by sponge carriers, these sounds were similat to those accompanying the final moment of prey capture in contexts where associated behaviour can be observed.

Female dolphins in Shark Bay vary considerably in the amount of time spent alone (SMOLKER et al. 1992; RICHARDS unpubl. data), with some females usually seen alone (or accompanied only by their dependent calf), and others usually found with other dolphins. Regular sponge-carrying dolphins are at the solitary end of this continuum. SMOTKER et al. (1992) analysed data on the proportion of days 25 of the most commonly sighted (nonsponge-carrying) females were sighted within parties (with at least one other individual other than her calf) versus outside of parties in 1988-1989. These females were in parties $31-86 \%$ of the days they were encountered $(\tilde{\mathrm{X}}=56 \%)$. Using the same methods, by comparison, the five sponge-carriers were sighted with other dolphins from 1984-1989 on $0-45 \%$ of the days they were seen $(\tilde{\mathrm{X}}=7 \%)$. This difference between sponge-carrying and non-sponge-carrying females was significant (Mann-Whitney $U=7$, two-tailed $p=0.0018$ ). When regular sponge carriers associated with others, it was typically for only a short period, and often with other sponge carriers.

Regular sponge carriers were not only relatively solitary, but also did not participate in the large 'leap-feeding' or socializing aggregations to which other dolphins in our study area were normally attracted. Leap-feeding involves large numbers of dolphins aggregating, often in association with birds, to feed on schools of fish.

The four cases of sponge carrying by non-regulars all involved well-known dolphins seen just once each with sponge, and all were seen many times without sponge before and after the sponge sighting. On 19 June 1986, PDX (female) was observed travelling over flats and into the channel where most sponge carrying is observed, when she surfaced just once with a sponge on her rostrum. On 6 July $1986 \mathrm{DBH}$ (probably female) was observed surfacing just once over a shallow (approx. $2 \mathrm{~m}$ ), sandy bottom with a sponge. The sponge was clearly held in her mouth and was described as 'flat and yellowish'. This observation occurred around the time it was also noted that she appeared emaciated, and she disappeared shortly thereafter. A third case involved one of the females provisioned with fish at the Monkey Mia campground (PUC). On 24 May 1986, PUC was observed and filmed engaging in typical sponge-carrying behaviour for $29 \mathrm{~min}$, while accompanied by a subadult male in the channel where most sponge carrying was observed. The sponge she carried appeared to be the same variety as those carried by regular sponge-carrying dolphins. $A$ fourth case, involving a male (SPU), was observed and filmed on 16 November 1988. SPU and two other males had chased a female, and after catching up with her, SPU was observed surfacing just once excitedly near her with a sponge on his rostrum. All of these observations were anomalous with respect to the usual behaviour of these animals. With the exception of the observation of PUC, all were very brief (one surfacing on one occasion) and did not otherwise resemble typical surfacing behaviour of regular sponge carriers.

Observing sponge carrying under water is extremely difficult. On two occasions, in an area northwest of the usual channel where most sponge carrying was observed, a combination of very calm weather and good underwater visibility permitted observations through the water surface of HAL carrying sponge. The water here was somewhat shallower (4-5 $\mathrm{m})$ and it was possible to see all the way to the bottom.

On 8 July 1990, A. RICHARDS observed HAL's behaviour intermittently over a period 
of $2 \mathrm{~h} 19 \mathrm{~min}$. She travelled over a sandy bottom dotted by occasional outcrops of rock, seaweed, and a few scattered corals, sometimes accompanied by her dependent calf. Throughout this period, she surfaced many times, both with and without the sponge. HAL travelled underwater more rapidly when she was carrying a sponge than when she did not have a sponge, so four of the six observations of her behaviour with the sponge were very brief. During the longest period of visibility with the sponge, she came to an outcrop of rock ledges where she paused and hung with her head down over the ledge for about 10 $s$ as she apparently investigated the ledges before moving out of sight.

HAL was visible more often when she did not have the sponge. On 13 occasions she was observed hanging motionless and horizontal at the bottom with her head slightly lower than her tail. She sometimes surfaced to breathe and then dove back to the same spot where she continued her vigil. Her attention appeared to be directed towards something a few metres ahead. In five cases this motionless stationing ended in an abrupt acceleration in the direction she had been facing. This burst of speed always took her out of sight. Shortly after one such acceleration she was seen at the surface swallowing something white. After the other four accelerations she was next seen surfacing slowly with the sponge about $10 \mathrm{~m}$ from where she had accelerated. All 13 cases of motionless hanging appeared to be the same sort of 'attending' to a distant spot. This attending behaviour and subsequent acceleration suggest that she had located a potential prey item and was monitoring its activity prior to a pursuit. HAL was observed retrieving her sponge from the bottom five times. In three of these five cases, she picked up the sponge just prior to tising to the surface.

On 8 July 1992, J. MANN observed HAL intermittently for 46 min in approximately the same location as the above observation. HAI was visible underwater with the sponge on four occasions, always travelling along close to the bottom. Three times it was noted that her head was angled down towards the sandy bottom. Once, she appeared to skim the sponge along the sandy bottom as she slowly travelled along. HAL was visible underwater without the sponge on five occasions. During each, her activity consisted of brief accelerations followed by headstanding (rostrum down and almost touching the bottom, body nearly vertical). Sometimes the headstand was suddenly broken off by a repeat of the acceleration-headstand sequence in another direction. We have observed similar behaviour by dolphins without sponges in shallower water (referred to as 'bottomgrubbing'). This differs from the 'attending' observed by A. RICHARDS in that HAL did not spend prolonged periods hanging motionless, orientated towatds a distant spot prior to the acceleration. As in the 1990 observations, HAL was always without the sponge when accelerating and headstanding but picked it up before resurfacing.

\section{Discussion}

Our data show that a small number of individuals from the overall population of dolphins in our study area consistently engage in sponge-carrying behaviour. These are all relatively solitary females that carry sponge mostly within a restricted deep-water channel. Observations of other dolphins with sponges were brief and anomalous except for one case where a very well-known female engaged in 'typical' sponge carrying once for half an 
hour. Regular sponge carriers appear to specialize in this behaviour. Exactly what the dolphins do with these sponges remains unknown, but below we consider three hypotheses regarding how sponges may be used and discuss them in light of our observations.

First, could the dolphins simply be playing with the sponges? Dolphins, both in captivity and in the wild, sometimes carry objects around, apparently using them for play. NORRIS (1991) reported a case involving a wild spinner dolphin, Stenella longirostris, that carried a piece of plastic draped over the pectoral fin, on its head, and occasionally transferring it between the pectoral fin and tail flukes. SLOOTEN \& DAWSON (1994) report Hector's dolphins, Cephalorbynchus bectorii, carrying and playing with seaweed. Dolphins in Shark Bay sometimes carry objects such as pieces of seagrass, carried on the fins or in the mouth, with which they engage in social games of 'keep away' (pers. obs.). CALDWELL \& CALDWELL (1987) reported captive dolphins, Tursiops truncatus, using shells in social play. When the dolphins stopped playing, they would swallow the shells, only to regurgitate them later for further play.

Sponge carrying by Shark Bay dolphins does not appear playful. Behaviour we consider to be 'play' is usually social and is typically accompanied by a wide variety of postures, splashing and vocalizations, behaviour patterns that do not accompany sponge carrying. Although solitary play could be more difficult to recognize as such, sponge carrying is methodical and stereotyped behaviour, engaged in primarily by a few, relatively solitary adult females for hours on end, year after year. This kind of time commitment, particularly by an adult (usually lactating: RICHARDS 1996) female is unlikely to be devoted to play and is more similar to the time spent foraging by dolphins that do not carry sponges.

Second, is it possible that the dolphins are extracting something from the sponges? Sponges are a well-known source of biologically active (e.g. antibacterial, antifungal, cytotoxic and antimitotic) "marine natural products" (FAUTIN 1988). For example, BERQUIST \& BEDFORD (1978) and HOOPER et al. (1992) have found antibacterial compounds in sponges from Australian waters. The discovery of these compounds has led to an increasing interest in sponges on the part of pharmaceutical industries. Meanwhile, studies of various terrestrial species have contributed to a growing field of 'zoopharmacognosy'; the study of how animals use plants and other objects in their environment for medicinal purposes (RODRIGUEZ \& WRANGHAM 1993). Given the known prevalence of such potentially medicinal compounds in sponges, it is feasible that the Shark Bay dolphins are exploiting a compound in the sponges they carry.

Although this possibility cannot be ruled out, it seems unlikely. There are no obvious indications that any part of the sponge is ingested, although this could be difficult to observe. If the sponges are used medicinally, the ailment for which they are used must be sex-specific (only affecting females) and chronic, because regular sponge carriers engage in the behaviour persistently over many years. All of the regular sponge carriers have reproduced successfully and appear healthy. Samples of Ecbinodictyum mesenterinum (not the samples we provided) have been tested against bacteria Escherichia coli, Bacillus subtilis and Saccharomyces cerevisiae, and proven ineffective (HOOPER et al. 1992). Further testing for other possible medicinal properties remains to be done.

Third, could the dolphins be using the sponges as an aid to some sort of foraging activity? Dolphins appear to forage while carrying sponges, as indicated by the fact that 
we see them occasionally consuming prey, that the time invested in carrying sponge is similar to that invested in foraging by non-sponge-carrying dolphins, that sounds produced by dolphins during sponge carrying are similar to those they produce during foraging in other contexts, and that their surface behaviour resembles foraging of non-sponge carriers. Regular sponge carriers appear to specialize in this foraging strategy. That regular sponge carriers rarely participate in other forms of feeding activities such as leap-feeding (even when this activity occurs close to the channel where most sponge carrying occurs) suggests that these females may be pursuing different prey species from other dolphins in the population. The high proportion of tail-out dives (indicating a steep descent) indicates that the prey are close to or at the bottom of the channel.

How could sponges be used as part of a foraging specialization? Dolphins in Shark Bay consume a wide variety of prey species, including cephalopods and both schooling and solitary fishes. Foraging strategies are also highly varied, including latge aggregations of dolphins and birds feeding on schooling fishes ('leap and porpoise feeding'), individual dolphins swimming upside down in pursuit of small garfishes at the water surface ('snacking') and individuals poking their rostra around into the weed and sandy bottom, flushing out prey concealed there ('bottom grubbing'). Both the surface observations (no sponge carried during ingestion of prey) and the underwater observations (no sponge carried during apparent monitoring of prey or bottom grubbing, but retrieved prior to travel or surfacing) indicate that the sponge may be useful during the search phase, but is dropped prior to pursuit and capture of prey.

A number of noxious organisms, including stonefish, scorpionfish, blue-ringed octopus, sea snakes and stingrays occur in Shark Bay, and potentially pose a threat to foraging dolphins. Sponges may serve to protect the dolphin's face from the spines or stingers of such organisms encountered while searching for prey. We do not know the extent to which dolphins encounter such organisms in Shark Bay, but stingray spines are a known significant cause of dolphin mortality in the Atlantic (WALSH et al. 1988), and we know of one case where a stingray spine may have caused death in a Shark Bay dolphin. Divers collecting sponge samples filmed the bottom of the channel where sponge carrying is usually observed. The bottom is swept by a fairly strong current and is composed of sand, broken shells and gravel with occasional small rocky outcrops around which fish shelter. Among the fishes observed in this area was the lionfish Pterois volituns. This fish possesses an extremely powerful toxin within spines that are erected when it becomes alarmed.

Sponges may also be used to disturb the bottom, flushing out prey species that burrow into the sandy bottom. J. MANN's observation of the dolphin 'skimming' the bottom with a sponge is consistent with this scenario, though more detailed observations are needed. Prolonged dragging or poking of the rostrum in the sand could cause abrasions, particularly if there are occasional sharp rocks or shells.

BECK (1980, p. 10) defines tool use as "the external employment of an unattached environmental object to alter more efficiently the form, position or condition of another object, another organism or the user itself, when the user holds or carries the tool just prior to use and is responsible for the proper and effective orientation of the tool." By this definition, use of a sponge to protect against abrasion, or stingers, or to flush out prey would qualify as tool use. The dolphins must detach the sponge from its substrate prior 
to use, but we do not know whether the sponges are otherwise modified prior to use or if the dolphins are selective in choosing individual sponges.

Tool use by dolphins has been previously reported. TAYLER \& SAAYMAN (1973) reported that a captive bottlenose dolphin used pieces of broken tile to rub along the tank walls, dislodging pieces of seaweed that were then consumed. A second dolphin in the same tank later began to do the same thing. BROWN \& NORRIS (1956) reported observing two captive bottlenose dolphins attempting to dislodge a moray eel from a crevice. After many attempts, one dolphin sought out and killed a scorpion fish, carried the fish to the crevice and poked at the eel with the spiny fish. The eel then abandoned the crevice and was caught by the dolphin.

In the Shark Bay population, only a small number of individual dolphins (all female) carry sponges regularly. This highly restricted specialization does not seem to have spread throughout the population as did, for example sweet potato and wheat washing by Japanese macaques (KAWAMURA 1959; KAWAI 1965). The observation of PUC carrying sponge indicates that some other members of the population are aware of the behaviour and may occasionally engage in it. The daughter of a regular sponge-carrying dolphin carries sponges herself now that she is independent of her mother. Similarly, most of the individuals that have taken advantage of the provisioning situation at Monkey Mia (also a 'foraging specialization') have been offspring of provisioned females.

Foraging specializations occur in a variety of species, including birds (oystercatchers: NORTON-GRIFFITHS 1967; GOSS-CUSTARD \& SUTHFRLAND 1984; robins: HERRERA 1978), fishes (KOHDA 1994), cetaceans (WEINRICH et al. 1985; HOELZEI et al. 1989; HARWOOD 1990; BAIRD et al. 1992) and sea otters (LYONS \& ESTES 1985). MAYNARD SMITH (1982) applied game-theoretical models to understand the costs and benefits of different strategies within populations. Forces leading to alternative strategies include situations where: 1 . individuals compete and the losers are forced to adopt an inferior strategy; 2. differences in phenotype result in different abilities to exploit resources; 3 . the 'best' strategy for an individual is determined by what strategies are adopted by other members of the population (mixed strategy maintained by frequency-dependent selection); and 4. the 'best' strategy depends on the individual's environment, for example, where food resources are patchily distributed within its range.

We do not see overt signs of feeding competition among dolphins in Shark Bay, though it may well occur. Shark Bay dolphins are not obviously sexually dimorphic in size, nor are there obvious phenotypic differences between sponge carriers and other dolphins. (One regular sponge carrier is missing half of her tail flukes, but other dolphins in the population also lack flukes or fins). Sponge carrying may be a strategy that requires a degree of solitary living not possible for males, for which the formation and maintenance of cohesive and cooperative alliances seem to be critical (CONNOR et al. 1992a, b). Most dolphins in Shark Bay appear to engage in various hunting strategies, but we know little about interactions between strategies. Sponge carrying may be a 'patch-specific' strategy. It is limited primarily to deep-water channels, where the flora and fauna appears to differ from that in adjacent shallow-water areas.

Sponge carrying is clearly a behavioural specialization engaged in consistently over many years by a very small subset of the Shark Bay dolphin population, all relatively solitary females. Although underwater observations have been difficult, the dolphins do appear to 
be foraging, and the hypothesis that sponges are used as foraging tools is most consistent with our observations. Future research should provide details of how sponges are used, how the behaviour is acquired, and the relative costs and benefits of sponge carrying as a foraging specialization.

\section{Acknowledgements}

Financial support for this work came from the National Geographic Sociery, Ann and Gordon GFTT, the Dolphins of Shark Bay Research Foundation, Sigma Xi, the New York Explorers Club, the National Science Foundation (grant BSN8601475 to R. CONNOR), the Chicago Zoological Society and University of Michigan (grants to A. RICHARDS). All are gratefully acknowledged. For help with fieldwork logistics we thank The University of Western Australia, particularly Dr Richard Hol.ST, the West Australian Museum, the Shire of Shark Bay, the ranger staff at Monkey Mia and the Department of Conservation and I and Management. For help with collecting sponges and filming the bottom, we thank members of the France-Australe Bicentenary Expedition and Andrew and Elizabeth WIGHT. Richard ALEXANimR, Mike HFTHAIS, John HOOPI:R, John MiTANI, John PEPPER and William MCGREW made helpful comments on the manuscript.

\section{Literature Cited}

ALTMANN, J. 1974: Observational study of behavior: sampling methods. Behaviour 49, $227-265$.

BAIRD, R. W., ABRAMS, P. A. \& DIL, I. M. 1992: Possible indirect interactions between transient and resident killer whales: implications for the evolution of foraging spccializations in the genus Orcinus. Oecologia 89, $125-132$.

BECK, B. 1980: Animal Tool Behavior. Garland STPM Press, Ncw York.

BFRQUIST, P. R. \& BEDFORD, J. J. 1978: The incidence of antibacterial activity in marine Demospongiae; systematic and geographic considerations. Mar. Biol. 46, 21 苂-221.

BRoWN, D. H. \& NORRIS, K. S. 1956: Observations of captive and wild cetaceans. Behaviour 37, $311-326$.

CAldwell, M. C. \& CALDWEl.L, D. K. 1987: Foreign object ingestion by Atlantic bottlenose dolphins; accident or design. Abstract: Seventh Bien. Conf. Biology of Marine Mammals. Dec. 1987, Miami.

CONNOR, R. C. \& SMOl.ker, R. 1985: Habituated dolphins (Tursiops sp.) in Western Australia. J. Mammal. 66, $398-400$.

CONNOR, R. C., SMOLKER, R. \& RiCHARDS, A. F. 1992a: Two levels of alliance formation among male bottlenose dolphins (Tursiops sp.). Proc. Nat. Acad. Sci. USA 89, 987-990.

$\ldots-\ldots \ldots$ 1992b: Dolphin alliances and coalitions. In: Coalitions and Alliances in Hurnans and Other Animals (Harcolirt, A. H. \& DewaAl, F. B. M., eds). Oxford Univ. Press, Oxford. pp. 415-443.

FALTIN, D. G. 1988: Biomedical importance of marine organisms. Memoirs Calif. Acad. Sci. 13, 1 - 159.

Goss-Custard, J. D. \& SUTHERI.AN1), W. J. 1984: Feeding specializations in oystercatchers (Haematopus ostralegus). Anim. Behav. 32, 299-300.

HARWOOD, J. 1990: Whales and seals are individuals. Trends Ecol. Evol. 5, 171.

HJERRFRA, C. M. 1978: Individual dietary differences associated with morphological differences in robins Erithacus rubecula. Ibis $120,542-545$.

HOELZEL, A. R., DORSEY, E. M. \& STERN, J. 1989: The foraging specializations of individual minke whales. Anim. Behav. 38, 786-794.

HoOper, J. N. A. 1991: Revision of the family Raspailiidae (Porifera: Demospongiae), with description of Australian species. Invert. Tax. 5, 1179-1418.

- - CAPRON, R. J., KEENAN, C. P., PARRY, D. L. \& SMIT, N. 1992: Chemotaxonomy of marine sponges: families Microcionidae, Raspailiidae and Axinellidae, and their relationships with other families in the orders Poecilosclerida and Axinellida (Porifera: Demospongiae). Invert. Tax. 6, 261-301,

KAWAI, M. 1965: Newly acquired pre-cultural behavior of the natural troop of Japanese monkeys on Koshima Islet. Primates 1, $1-30$.

KAWAMLRA, S. 1959: The process of subculture propagation among Japanese macaques. Primates 2, 43-60. 
KOHDA, M. 1994: Individual specialized foraging repertoites in the piscivorous cichlid fish Lepidiolamprologus profundicola. Anim. B thav. 48, 1123-1131.

LYONS, K. J. \& ESTFS, J. A. 1985: Individual variation in dict and foraging strategy in the female California sea otter (Enhydra lutris). Paper pres. 66th Ann. Meeting Western Soc. Naturalists, Monterey.

MANN, J. 1995: Natal attraction and imprinting in wild bottlenose dolphins (Tursiops truncatus): the babysitting myth. Abstract: Fleventh Bien. Conf. Biology of Marine Mammals, Dec. 1995, Orlando.

MAYNARD SMITH, J. 1982: Evolution and the Theory of Games. Cambridge Univ. Press, Cambridge.

NorRis, K. S. 1991: Dolphin Days: The Life and Times of the Spinner Dolphin. Norton \& Co, New York.

NORTON-GRIFFITHS, M. 1967: Some ecological aspects of the feeding behavior of the oystercatcher haematopus ostralegus on the edible mussel Mytilus edultis. Ibis $109,412-424$.

OVERSTROM, N. A. 1983: Association berween burst-pulse sounds and aggressive behavior in captive Atlantic bottlenose dolphins (Tursiops truncatus). Zoo Biol. 2, 93-103.

RichardS, A. F. 1996: Life history and behavior of female dolphins (Tursiops sp.) in Shark Bay, Western Australia. PhD thesis, Univ. of Michigan, Ann Arbor. Univ. Microfilms.

RODRIGUeZ, E. \& WRANGHAM, R. W. 1993: Zoopharmacognosy: the use of medicinal plants by animals. Rec. Adv. Phytochemistry 27, 89-106.

SLoOTfN, L. \& DAwSON, S. 1994: Hectors dolphins. In: Handbook of Marine Mammals, Vol 5 (Rn)GwAY, S. H. \& Harrison, R., eds). Acad. Press, London. pp. 311-334.

SMOLKF, R. 1993: Acoustic communication of bottlenose dolphins. PhD thesis, Univ. of Michigan, Ann Arbor. Univ. Microfilms.

- -, RiChaRds, A. F., CONNOR, R. C. \& PEPPER, J. 1992: Sex diffetences in patterns of association among Indian Ocean bottlenose dolphins. Behaviour 123, 38-69.

TAYI.FR, C. K. \& SAAYMAN, G. S. 1973: Imitative behavior by Indian Ocean bottlenose dolphins (Tursiops aduncus) in captivity. Behaviour 44, 286-298.

Walsh, M. T., Belsse, D., Bossart, G. D., Young, W. G., Odhi., D. K. \& PATTON, G. W. 1988: Ray encounters as a mortality factor in Atlantic bottlenose dolphins (Tursiops truncatus). Mar. mammal Sci. 4, $154-162$.

WEINRICH, M. T., BELT, C. R., IKEN, H. J. \& SCHILLING, M. R. 1985: Individual variation in feeding patterns of humpback whales (Megaptera novatangliae) in New England. In: Humpback Whales of the Southern Gulf of Maine. Cetacean Res. Unit, Gloucester. pp. 23-32.

Received: June 6, 1996

Accepted: November 18, 1996 (J. Brockmann) 